\title{
THE ROLE OF SELF-IMAGE AND MOTIVATION IN SPORTS PERFORMANCE
}

\author{
Ileana Monica POPOVICI ${ }^{*}$, Cristina Elena MORARU1 \\ 1 “Alexandru Ioan Cuza” University, Faculty of Physical Education and Sport, Iași, Romania \\ *Corresponding address: ileana.popovici@uaic.ro
}

DOI: 10.35189/iphm.icpesk.2019.30

\begin{abstract}
The current paper aims to conduct an analysis on the implications of motivation and self-image in shaping the performance path of an athlete by formulating certain suggestions regarding this topic. The hypothesis of the research is that intrinsic motivation and self-image are better developed in performance athletes compared to athletes who have failed to obtain notable results. For this research, we benefited from the participation of 112 university students, of whom 54 were athletes with great performances, while 58 failed to obtain remarkable results. For this study, we used the following instruments: the Rosenberg Self-Esteem Scale and the Intrinsic Motivation Scale from the Intrinsic and Extrinsic Motivation Questionnaire (Amabile, 1983, adapted by Stoica-Constantin and Constantin). Findings: Based on the statistical analyses, we have found significant differences between the performance group and the control group in terms of both self-image [t $(110)=3.429, p<0.05]$ and intrinsic motivation $[t(110)=5.404, p<0.05]$, which confirms the hypothesis of the research. Consequently, we emphasise the importance of forming a positive self-image and a motivational optimum among athletes, because these factors will always determine the achievement of remarkable performances, thus paving the way for success in the case of athletes.
\end{abstract}

Keywords: motivation, self-image, performance.

\section{Introduction}

Nowadays, human personality is making its existential way by trying to redefine and re-evaluate the fundamental strategies of living and the current moral values in the new socioeconomic and cultural context of the postmodern society. We all know that the psychological factor is essential in any particular human performance, but we will have to find the way in which this factor ensures the self-balance of a human being and their ability to adapt to the material and social environments that are constantly changing and obviously to the need for performance.

It is known that athletic performance bears the influence of two categories of factors: internal and external, which are revealed depending on each athlete's personality. In this paper, we focused on two important factors: self-image and motivation.

\section{Self-image}

From a sociological perspective, the reflexive self develops in the interaction with others through a process that includes a person's self-efficacy, self-image, self-concept and self-esteem (Falk \& Miller, 1998).

Self-image is the way you see yourself. This may be the way you perceive yourself physically or your opinion of who and what you are, which is usually called self-concept. It is important, given that it affects your self-esteem and confidence. Self-image includes: what you think you look like; how you see your personality; what kind of person you think you are; what you believe others think of you; how much you like yourself or you think others like you; the status you feel you have. The way you see yourself is crucial, because this will affect your behaviour, your thinking and how you relate to others. People respond to you either in a positive or in a negative way, depending on how confident you are. Your confidence in relationships depends on your self-perceived image. (Nair, 2016, p. 75)

Self-image (self-concept) can be seen as a broader term that involves self-respect (self-worth) and consists of two parts: one's own perceived value - the belief that we have the right to be happy and that we deserve to be successful; hence, the belief that we can think, learn, choose, make decisions and overcome challenges and changes. All of this helps a person lead a better life, given that, with it, we can explain our past and current behaviour and predict our own future behaviour. In its absence, our behaviour would appear unpredictable, inexplicable and chaotic to ourselves. (Miljković \& Rijavec, 1996, p. 67) This is why education for a positive self-image in the school context is crucial. There are several factors that have an influence on repeated failures, among which self-criticism and the reactions of 
others to our actions, that is through introspection, by observing our own behaviour and receiving information from others about what surrounds us (Yahaya \& Ramli, 2009; Lebedina-Manzoni \& Lotar, 2011).

Creating one's self-image is the result of the cognitive process, which takes place when interacting with the other. According to Baron and Byrne (1997), this segment of the cognitive process is called social perception and refers to how a person gets to form their self-image and also how their impressions and opinions about others are built. In fact, it is about the two sides of the same problem: the individual approaches another person starting from themselves, just as the representation of another person is part of the process of self-perception.

Creating one's self-image is based on a type of information that results from self-perception and self-knowledge. The context of creating self-image is a social one, but the factors acting in this context can influence in a negative way the formation process.

Following a research on the psychosocial implications of self-image, Bogatu (1981) reaches the conclusion that, in its structuring, the level of education and the factors that have contributed to the socialisation of the individual have a decisive importance: social and family environments, cultural influences, past social events, but also a range of internal factors concerning the existence of neuropsychic traits and structures, and the personality type.

When relating to others, the precise appreciation and interpretation of self-image have a remarkable importance. Self-image has the role of orienting attitudes and behaviours in the context of interpersonal relationships, ensuring continuity, adaptation and efficiency (Bogatu, 1981, p. 65). At the same time, it implies a confrontation between the subject and the world, with the purpose of achieving an identity (Ceauşu, 1983, p. 34).

Self-image represents an important dimension in the complex structure of the personality and plays an essential role in the successful path of an athlete. Early success creates a sense of efficiency and contributes to reinforcing the ego and positive self-image, thus making the future failure more bearable: if it does occur, the young athlete will strive harder to achieve their usual goals; they will have an acceptance attitude towards risk, maximising their chances of success and self-image consolidation. In the case of early repetitive failures, a negative self-image emerges and it is very hard to remodel it, which usually leads to poor results in the future.

A good self-image can be built, for example, if the young person's character routinely leads them to convert measurable setbacks into measurable accomplishments. By doing so, the youth builds self-confidence in one area of great importance for that person (Bailey, 2003).

Self-esteem is a core construct in clinical psychology, as well as in developmental, personality and social psychology. The role it plays in psychological functioning has been studied for more than a hundred years.

Throughout the short history of psychology, few personality constructs have received greater theoretical and empirical attention than self-esteem. In 2004, Heine and Lehman stated that over 18,000 studies investigating selfesteem had been published over the past 35 years (this is a rate of more than one publication per day!). Meanwhile, the number of psychologists interested in self-esteem has grown exponentially over the years. Research on self-esteem has had a long and prolific history in psychology (Abdel-Khalek, 2016, p. 2).

Self-esteem concerns personal beliefs regarding skills, abilities and social relationships. Self-esteem is also defined as a global barometer of self-evaluation involving cognitive appraisals about general self-worth and affective experiences of the self, which are linked to these global appraisals (Murphy, Stosny, \& Morrel, 2005).

Self-esteem can refer to the overall self or to specific aspects of the self, such as how people feel about their social standing, racial or ethnic group physical features, athletic skills, job or school performance. Theorists have made many distinctions between different types of self-esteem, for example: contingent vs. non-contingent; explicit vs. implicit; authentic vs. false; stable vs. unstable; global vs. domain-specific. Regarding the dimensionality of self-esteem, some authors have conceptualised it as a unitary global trait, whereas others view it as a multidimensional trait with independent subcomponents (performance, social and physical self-esteem). (Heatherton \& Wyland, 2003)

\section{Motivation}

Everything we achieve is governed by motivation (nothing we do lacks motivation). Every action we undertake, even our own behaviour and attitude, needs motivation, direction and energy resources to be started. Therefore, motivation is a fundamental facet of personality, an internal variable with the role of supporting the beginning and development of various processes and psychological abilities, the individual's outer reactions. (Albu, 2002, p. 54) 
Motivation consists of a mixture of dynamic factors that determine the individual's behaviour, involving physical, chemical, physiological, motor, mental and emotional-volitional changes. It transforms the human being from a simple receiver of external influences into an active and selective individual, who has internal determinism in choosing and starting actions and behaviours (Albu, 2002, p. 54), playing the role of a filter through which we become permeable, from a psychological point of view, only to those stimuli that can satisfy our need. Because of its steering and tensional character, motivation ravages, settles sediments and amplifies the individual's psyche.

Most authors in the scientific literature agree with the following structures and forms of motivation. Structure of motivation: needs, reasons, interests, beliefs, ideals, world and life outlook. Forms of motivation: positive and negative motivation, intrinsic and extrinsic motivation, cognitive and emotional motivation, habitual and actual motivation.

Motivation study shows a real interest in how to achieve success in every action in which we participate. The relationship between a certain level of motivation intensity and a certain level of task difficulty is called motivational optimum. To be optimally motivated means to be mobilised so as to obtain maximum efficiency in the activity.

Reaching the state of optimal motivation depends on a series of factors such as: how we perceive the difficulty and complexity of the task, how we evaluate our possibilities (underestimation, correct appraisal and overestimation), the type of nervous system (weak or strong), personality factors (the type of temperament, character features). As to the way of perceiving the complexity of some actions, we can say that, in simple tasks, when the intensity of motivation increases, the performance level also increases, while in complex tasks, an increase in motivation is associated with an increase in performance level, but if the level of intensity is too high, performance decreases. This law is known as the "Yerkes-Dodson law". When the difficulty of a task is correctly perceived, there are proper conditions for athletes to obtain higher results in the actions performed.

When talking about athletes, the motivational problem is very sensitive. Generally, athletes with a strong intrinsic motivation have the tendency to become self-aware and independent and to finish what they have started. This explains why one can work better with athletes with intrinsic motivation. The extrinsic motivation of an athlete comes in the form of an improvement or degradation of the behaviour. Improvement behaviour appears when money, trophies and public recognition are involved. Degradation behaviour appears when punishment is involved. Most of the times, the athlete's motivation is ambivalent: intrinsic and extrinsic. It is obvious that the weight of the two types of motivation differs from one person to another.

Motivation is a challenge for virtually all athletes at some point in their careers. These challenges can become manifest through athletes' definitions of success, attributions for success and failure, lack of self-efficacy, lack of competence, autonomy or relatedness, lack of expectancies for future success, lack of task value, and any combination thereof. Fortunately, there are various ways to address athletes' motivational challenges. In addition to the theorybased approaches presented above, the specific techniques used in sport psychology will probably improve athlete motivation. Specifically, goal setting, cognitive restructuring, and imagery tend to be useful skills for athletes to learn for both motivation and overall performance improvement. Working effectively with athletes requires specific knowledge and training. Whether working with athletes at elite, recreational or other levels, the work can be highly rewarding. With the assistance of qualified sport psychologists, athletes can overcome their challenges, learn skills to perform at their peak, and eventually transfer those skills to their lives after sport (Peters \& Stefanek, 2011, p. 431).

Someone who has intrinsic motivation is inspired to be active in sport without being driven by any external incentive. The feelings of individuals performing activities that are enforced by intrinsic motivation include independence and competence. (Kingston, Horrocks, \& Hanton, 2006)

Studies of extrinsic motivation report that men seem to be more motivated by competition and playing to the limit (Recours, Souville, \& Griffet, 2004) compared to women as regards participation in sport. The behaviours resulting from extrinsic motivation do not always entail habits in intrinsic motivation (Kilpatrick, Hebert, \& Bartholomew, 2005).

van Heerden (2014) argued for the existence of a correlation between several motivation incentives and sport participation. In addition, the author studied the gender variable and whether there were differences between male and female athletes regarding their motivation for participating in sport. No significant differences were found between the gender groups and their motivation for sport participation. 


\section{Material and Methods}

The current paper aims to conduct an analysis on the implications of motivation and self-image in shaping the performance path of an athlete by formulating certain suggestions regarding this topic.

\section{Hypotheses of the research}

Main hypothesis: High-level athletes have a more developed self-image and intrinsic motivation compared to athletes who do not have remarkable results and high-level athletes have a less developed extrinsic motivation compared to athletes who do not have remarkable results.

Specific hypothesis 1: High-level athletes have a more developed self-image compared to athletes who do not have remarkable results.

Specific hypothesis 2: High-level athletes have a more developed intrinsic motivation compared to athletes who do not have remarkable results.

Specific hypothesis 3: High-level athletes have a less developed extrinsic motivation compared to athletes who do not have remarkable results.

\section{Research sample}

The research was carried out between October and December 2018. The subjects are 112 students from the Faculty of Physical Education and Sport in Iaşi (full-time education, from the first to the third year of undergraduate studies). Of them, 54 are athletes with remarkable results in the practiced sports, and 58 are athletes without remarkable results.

The dependent variable - the group variable, which has two 2 categories (performance group and control group)

The independent variable - self-image, intrinsic motivation (with its two dimensions: intrinsic motivation by pleasure and motivation by challenge) and extrinsic motivation (with its two dimensions: extrinsic motivation by recognition and by reward)

\section{Tests used in the research}

- To measure self-image, we used the Rosenberg Self-Esteem Scale, which measures the general feeling of selfworth, therefore global self-esteem, and identifies the level of confidence in one's own abilities and the level of satisfaction with personal achievements.

- To measure intrinsic and extrinsic motivation, we used the Intrinsic Motivation Scale from the Intrinsic and Extrinsic Motivational Questionnaire created by Amabile (1983) and calibrated to the Romanian population by Stoica-Constantin and Constantin. The scale was adjusted to measure intrinsic motivation in sports (it contains 2 dimensions, motivation by pleasure and motivation by challenge) and extrinsic motivation in sports (it also contains 2 dimensions, motivation by recognition and motivation by reward).

\section{Results}

Specific hypothesis 1

In order to verify this hypothesis, we applied the t-test for independent samples. The hypothesis was confirmed. Based on the statistical analyses obtained, we found significant differences between the group of high-level athletes and the control group in terms of self-image [ $\mathrm{t}(110)=3.429, \mathrm{p}<0.05$ ], high-level athletes with remarkable results having a better self-image compared to athletes without remarkable results in the practiced sports.

\section{Specific hypothesis 2}

In order to verify this hypothesis, we applied the t-test for independent samples. The hypothesis was confirmed. We found significant differences between the group of high-level athletes and the control group in terms of intrinsic motivation $\mathrm{t}(110)=5.404, \mathrm{p}<0.05$ ], high-level athletes with remarkable results being more intrinsically motivated compared to athletes without remarkable results in the practiced sports.

A deeper analysis of the results for each dimension of intrinsic motivation shows that intrinsic motivation differs between the two groups in favour of high-level athletes. So, they are more motivated by pleasure $[\mathrm{t}(110)=4.917, \mathrm{p}<$ 
$0.05]$ and by challenge [ $\mathrm{t}(110)=4.917, \mathrm{p}<0.05]$ compared to athletes without remarkable results in the practiced sports.

\section{Specific hypothesis 3}

In order to verify this hypothesis, we applied the t-test for independent samples. The hypothesis was confirmed. We found significant differences between the group of high-level athletes and the control group in terms of extrinsic motivation [t $(110)=-2.953, \mathrm{p}<0.05]$. So, high-level athletes are less extrinsically motivated for obtaining remarkable results compared to athletes without remarkable results in the practiced sports.

A more detailed analysis of the results for each dimension of extrinsic motivation shows that extrinsic motivation differs between the two groups, being less developed in high-level athletes. So, high-level athletes are less motivated by reward [ $\mathrm{t}(110)=-3.248, \mathrm{p}<0.05]$ and by recognition $[\mathrm{t}(110)=-2,322, \mathrm{p}<0.05]$ compared to athletes without remarkable results in the practiced sports.

A comparative presentation of average scores achieved for self-image and motivation by group variable is shown in Figure 1.

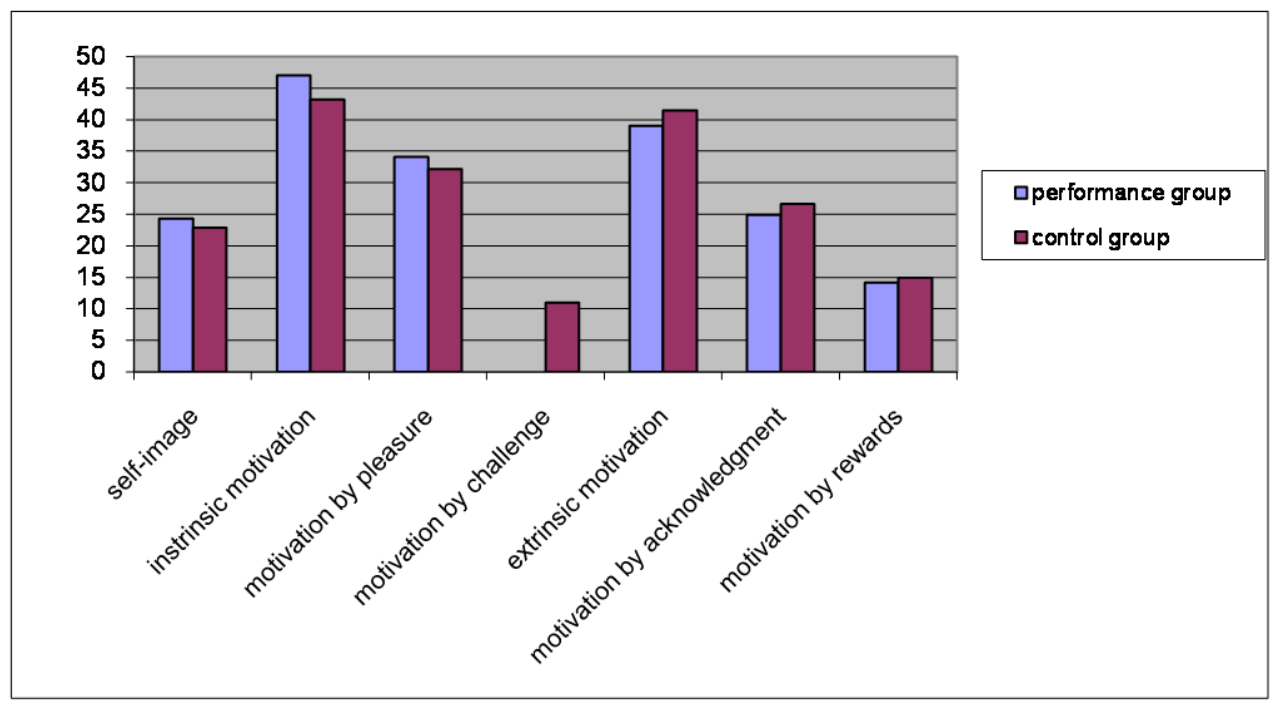

Figure 1. A comparative presentation of average scores achieved for self-image and motivation by group variable

\section{Discussion}

Suggestions regarding the development of self-image and emotional balance for the optimisation of sports results

The coach's role becomes very important in forming the athlete's correct and positive self-image. A coach must know athletes very well, their possibilities and (physical and psychological) limits to properly evaluate and help them by using appreciations and constructive remarks in order to outline their positive self-image. It is very important for the coach to take action very early in the future athlete's activities rather than when they are already engaged in major competitions. The coach's intervention may not be effective at that moment, because anxiety and stress specific to such competitions will overwhelm the athlete with a distorted self-image.

Early success creates a sense of efficiency and contributes to reinforcing the ego and positive self-image, thus making the future failure more bearable: if it does occur, the young athlete will strive harder to achieve their usual goals; they will have an acceptance attitude towards risk, maximising their chances of success and self-image consolidation. In the case of early repetitive failures, a negative self-image emerges and it is very hard to remodel it, which usually leads to poor results in the future. 
Positive self-image works as a behaviour-balance mechanism aiming to achieve success especially for elite athletes. Sport success can be determined by the effect of the results on athletes in relation to their personal skills and the connection between training strategies and self-image.

Most of the times, the athlete's motivation is ambivalent: intrinsic and extrinsic. It is obvious that the weight of the two types of motivation differs from one person to another. Applying the reinforcement law in the case of extrinsic motivation can be efficient in modifying the athlete's behaviour. For a coach, rewards and extrinsic motivation have to be seen as means that, if efficiently used, can contribute to the development of intrinsic motivation.

Practically, the purpose of a coach should be to turn extrinsic motivation into intrinsic motivation.

Therefore, in order to motivate athletes, certain steps can be followed:

1. Offering a strong extrinsic motivation to increase their interest in a certain sport.

2. Creating conditions for quick results, hence for increasing the level of self-perceived competence.

3. Systematic development of intrinsic motivation by developing the feeling of satisfaction provided by selfachievement.

It is very important that rewards are not in excess and do not create the image of a coach who tries to manipulate them. Athletes perceive this kind of behaviour as being negative. Rewards have to correspond to their achievements and training results and should not be given at random. Rewarding all athletes just for their participation in a competition, without remarkable results, cannot be transformed into intrinsic motivation. Athletes need to be aware that extrinsic rewards only mark successful moments and that the true motivation in a sports activity has to be their pleasure and satisfaction.

\section{Conclusion}

The complexity of the interrelation that appears between the internal and external factors induces a multiple determination in the development of athletes' talent. We emphasise that the personality factors specific to athletes with high potential have a central role in obtaining important results. Of these factors, we focused on self-image, which, according to the scientific literature, has a major contribution to achieving performance. Self-worth, underestimation and realistic self-assessment help consolidate the formative process for talented children and young people involved in the sports field. Self-image is a dynamic and evolving process that can be influenced by a specialised complex psychopedagogical assistance programme. Self-image is the standard around which young athletes evaluate their accomplishments and failures.

The motivational factor has a great importance in sports success. Proper motivation will determine excellent results, just as under-motivation and over-motivation will almost always lead to failure.

The investigation steps were conducted as empirical support for the theoretical considerations, showing that highlevel athletes have a better self-image compared to athletes without remarkable results in the practiced sports. Highlevel athletes are more intrinsically motivated (by pleasure, as well as by challenge) to obtain remarkable results in the practiced sports compared to athletes who do not have remarkable results. Also, high-level athletes are less extrinsically motivated (by recognition, as well as by reward) to obtain remarkable results compared to athletes who do not have remarkable results in the practiced sports.

Therefore, we believe that a positive self-image and proper motivation will always determine the achievement of remarkable results, thus creating a successful path for athletes to follow in the future.

The need of creating and implementing a specialised psycho-pedagogical assistance programme (for which coaches and sports psychologists are responsible) will lead to a decisive improvement of the young athletes' self-image and motivational balance, which will eventually help them achieve remarkable results in the sports field and daily life.

\section{References}

Abdel-Khalek, A. M. (2016). Introduction to the psychology of self-esteem. In F. Holloway (Ed.), Self-esteem: Perspectives, influences, and improvement strategies (pp. 1-23). New York: Nova Science.

Albu, G. (2002). In căutarea educaţiei autentice [In search of authentic education]. Iaşi: Polirom. 
Amabile, T. M. (1983). Effects of motivational orientation on creative writing. Paper presented at the Meeting of the American Psychological Association, Anaheim, California, August 1983.

Bailey, J. A. (2003). Self-image, self-concept, and self-identity revisited. Journal of the National Medical Association, 95(5), 383-386. Retrieved from https://www.ncbi.nlm.nih.gov/pmc/articles/PMC2594523/

Baron, R. A., \& Byrne, D. (1997). Social psychology ( $8^{\text {th }}$ ed.). Boston: Allyn \& Bacon.

Bogatu, N. (1981). Implicaţii psihosociale ale imaginii de sine [Psychosocial implications of self-image]. Revista de Psihologie, 4, 26-29.

Ceauşu, V. (1983). Autocunoaşstere şi creaţie [Self-knowledge and creation]. Bucureşti: Editura Militară.

Falk, R. F., \& Miller, N. B. (1998). The reflexive self: A sociological perspective. Roeper Review, 20(3), 150-153. https://doi.org/10.1080/02783199809553881

Heatherton, T. F., \& Wyland, C. L. (2003). Assessing self-esteem. In S. J. Lopez \& C. R. Snyder (Eds.), Positive psychological assessment (pp. 219-233). Washington, DC, US: American Psychological Association.

Heine, S. J., \& Lehman D. R. (2004). Move the body, change the self: Acculturative effects on the self-concept. In M. Schaller \& C. S. Crandall (Eds.), The psychological foundations of culture (pp. 305-331). Mahwah, New Jersey, London: Lawrence Erlbaum Associates, Publishers.

Kilpatrick, E. H., Hebert, E., \& Bartholomew, J. (2005). College students' motivation for physical activity: Differentiating men's and women's motives for sport participation and exercise. Journal of American College Health, 54(2), 87-94. https://doi.org/10.3200/JACH.54.2.87-94

Kingston, K. M., Horrocks, C. S., \& Hanton, S. (2006). Do multidimensional intrinsic and extrinsic motivation profiles discriminate between athlete scholarship status and gender? European Journal of Sport Science, 6(1), 53-63. https://doi.org/10.1080/17461390500440889

Lebedina-Manzoni, M., \& Lotar, M. (2011). Percepcija sebe kod adolescenata u Hrvatskoj [Adolescent self-perception in Croatia]. Kriminologija i Socijalna Integracija, 19(1), 39-50. Retrieved from https://hrcak.srce.hr/67788

Miljković, D., \& Rijavec, M. (1996). Razgovori sa zrcalom: Psihologija samopouzdanja [Conversations with the mirror: The psychology of self-confidence]. Croatia: IEP.

Murphy, C. M., Stosny, S., \& Morrel, T. M. (2005). Change in self-esteem and physical aggression during treatment for partner violent men. Journal of Family Violence, 20(4), 201-210. Retrieved from https://www.researchgate.net/deref/http\%3A\%2F\%2Fdx.doi.org\%2F10.1007\%2Fs10896-005-5983-0

Nair, R. J. (2016). Self-image and self-esteem for a positive outlook. In Training manual on Theeranaipunya Equipping fisherwomen youth for future (pp. 75-78). Retrieved from https://www.researchgate.net/publication/303702365_Self-Image_and_Self-Esteem_for_a_Positive_Outlook

Peters, H. J., \& Stefanek, K. A. (2011). Motivation in sport: Theory and application. In W. Miles Cox \& E. Klinger (Eds.), Handbook of motivational counseling ( $2^{\text {nd }}$ ed.) (pp. 415-435). Wiley-Blackwell.

Recours, R. A., Souville, N., \& Griffet, J. (2004). Expressed motives for informal and club association-based sports participation. Journal of Leisure Research, 36(1), 1- 22. DOI: 10.1080/00222216.2004.11950008

van Heerden, C. H. (2014). The relationships between motivation type and sport participation among students in a South African context. Journal of Physical Education and Sport Management, 5(6), 66-71. DOI: 10.5897/JPESM2013.0181

Yahaya, A., \& Ramli, J. (2009). The relationship between self-concept and communication skills towards academic achievement among secondary school students in Johor Bahru. International Journal of Psychological Studies, 2(2), 25-34. Retrieved from http://eprints.utm.my/id/eprint/9766/ 